\title{
A Educação Matemática Inclusiva no Brasil: uma análise baseada em artigos publicados em revistas de Educação Matemática
}

\author{
Angela Meneghello Passos \\ Marinez Meneghello Passos \\ Sergio de Mello Arruda
}

\section{Resumo}

Este artigo apresenta uma análise qualitativa da produção bibliográfica brasileira sobre a Educação Matemática Inclusiva. O corpusfoi composto por artigos publicados em quatro revistas da área de Educação Matemática: Boletim Gepem, Bolema, Zetetiké e Educação Matemática Pesquisa. A análise dos periódicos considerados mostra que hápouca pesquisa sobre a inclusão nas aulas de Matemática. Além disso, as investigações centram-se principalmente na aprendizagem de alunos com necessidades educacionais especiais e quase nada foi publicado sobre o ensino nesses contextos. Conclui-seque a Educação Matemática Inclusiva no Brasil é uma linha de pesquisa recente, a qual requer uma quantidade maior de investigação para que algum conhecimento sobre este campo possa ser útil para a melhoria do ensino e da aprendizagem da Matemática em salas de aula inclusivas.

Palavras-chave: Educação Matemática Inclusiva. Formação de professores. Análise textual discursiva.

\begin{abstract}
This paper presents a qualitative analysis of the Brazilian bibliographic production on Inclusive Mathematics Education. The corpus was composed of papers published in four journals of Mathematics Education: Boletim Gepem, Bolema, Zetetiké e Educação Matemática Pesquisa. The analysis of the considered journals shows that there is little research on the inclusion in mathematics classes. Furthermore, the investigations focus mainly on learning of students with special educational needs and almost nothing has been published on the teaching in these contexts. It is concluded that Inclusive Mathematics Education in Brazil is a recent line of research which requires a greater amount of research that some knowledge about this field can be useful for improving the teaching and learning of Mathematics in inclusive classrooms.
\end{abstract}

Keywords: Inclusive Mathematics Education. Teachers' Education. Discursive Textual Analysis. 


\section{Introdução}

O questionamento que deflagrou essa pesquisa está relacionado ao fato de que a inclusão de alunos com necessidades educacionais especiais se faz realidade nos estabelecimentos de ensino em todas as unidades de federações brasileiras.

Acredita-se que uma análise da produção bibliográfica brasileira em revistas da área de Educação Matemática e que tenha a inclusão como foco, possa evidenciar particularidades desse fenômeno. Diante do exposto, neste artigo busca-se responder à seguinte questão: o que se produz no Brasil a respeito de uma Educação Matemática Inclusiva?

A pergunta lançada estava aberta, pois não se sabia o que seria encontrado, apesar de o olhar dos autores estar voltado para o que se produz sobre inclusão, relacionado à formação dos professores especialistas de Matemática que trabalham em salas inclusivas.

Espera-se que os resultados possam evidenciar significados, indicar tendências e movimentos, caracterizar aspectos próprios desse campo (considera-se o termo campo como 'área em que se desenvolve alguma atividade', neste caso, pesquisas e/ou projetos relativos à Educação Matemática Inclusiva) de pesquisa, vinculado especificamente à área em estudo.

\section{Educação inclusiva no Brasil}

Na sequência, apresentam-se algumas informações a respeito de como o ensino de pessoas com deficiência foi discutido e sistematizado, por meio de leis, decretos, estatutos, diretrizes, entre outros, em nosso país.

No Brasil, tem-se atendimento às pessoas com deficiência desde a época do Império. Em meados do século XIX é fundado o Imperial Instituto dos Meninos Cegos, atual Instituto Benjamin Constant; e o Instituto dos Surdos e Mudos, hoje Instituto Nacional da Educação dos Surdos, ambos no Rio de Janeiro.

Em 1926 é criado o Instituto Pestalozzi, em Canoas, no Rio Grande do Sul, especializado na educação especial na área da deficiência mental. Em 1954 surge, no Rio de Janeiro, a primeira Associação de Pais e Amigos dos Excepcionais - APAE.

No ano de 1961, a Lei de Diretrizes e Bases da Educação Nacional - LDBEN, Lei no $4.024 / 61$, fundamenta o atendimento educacional às pessoas com deficiência dentro do sistema geral de ensino. Na década de 70, do século passado, a Lei 5.692/71 que altera a LDBEN de 1961, reforça ainda mais o encaminhamento dos alunos especiais para as classes e escolas especiais. $\mathrm{E}$ também, o MEC cria um centro para gerenciar a educação especial no Brasil, o CENESP - Centro Nacional de Educação Especial. 
Realizando uma retrospectiva da política pública democrática a respeito da Educação Inclusiva no Brasil, encontra-se como documento pioneiro nesta área, a Constituição Federal de 1988, artigo 208, item III.

Art. 208 - O dever do Estado com a educação será efetivado mediante a garantia de: III

- atendimento educacional especializado aos portadores de deficiência, preferencialmente na rede regular de ensino; [...].

A partir da constituição pode-se citar entre os principais documentos sobre a Educação para pessoas com necessidades educacionais especiais:

- a Lei 7.853 de 1989, que trata do apoio às pessoas portadoras de deficiência e sua integração social;

- o Estatuto da Criança e do Adolescente de 1990;

- a Declaração de Salamanca, de 10 de junho de 1994, que relata sobre os princípios, políticas e práticas na área das necessidades educacionais especiais;

- a Lei de Diretrizes e Bases da Educação Nacional de 1996, que descreve sobre a Educação Especial em seu capítulo V;

- o Decreto no 3.298 de 1999, que regulamenta a Lei 7.853 de 1989 da Política Nacional para a Integração da Pessoa Portadora de Deficiência;

- o Plano Nacional de Educação de 2001, com os objetivos e as metas para a educação das pessoas com necessidades educacionais especiais;

- as Diretrizes Nacionais para a Educação Especial na Educação Básica de 2001;

- a Resolução do Conselho Nacional de Educação no 1/2002, que institui Diretrizes Curriculares Nacionais para a Formação de Professores da Educação Básica, em nível superior, curso de licenciatura, de graduação plena;

- a Política Nacional de Educação Especial na perspectiva da Educação Inclusiva de 2007;

- o Decreto número 6.571 de 2008, que dispõe sobre o atendimento educacional especializado.

A partir dessa retrospectiva das políticas públicas brasileiras e da observação dos Censos Escolares, percebe-se que ocorre a cada ano um aumento do número de alunos que necessitam de atendimento especializado matriculados nas classes comuns das escolas regulares. Esse resultado vem ao encontro do objetivo da Política Nacional de Educação Especial na Perspectiva Inclusiva que é o acesso, a participação e a aprendizagem dos alunos com necessidades especiais nas escolas regulares.

R. B. E. C. T., vol 6, núm. 2, mai-ago.2013 ISSN - 1982-873X 
Essa política pública, em vigência, também tem como objetivo orientar os sistemas de ensino nessa inclusão, garantindo, entre outros pontos, a:

Formação de professores para o atendimento educacional especializado e demais profissionais da educação para a inclusão escolar. (BRASIL, 2008, p.14)

O Decreto número 6.571 de 2008, que dispõe sobre o atendimento educacional especializado, relata que o Ministério da Educação prestará apoio técnico e financeiro aos sistemas públicos de ensino e, também, proporcionará formação continuada de professores para $\mathrm{o}$ atendimento educacional especializado.

\section{Formação de professores no contexto da educação inclusiva}

Em decorrência de uma Educação Inclusiva algumas reestruturações no contexto escolar se fazem necessárias, como: adequação arquitetônica de prédios escolares, mobiliários e equipamentos; elaboração, produção e distribuição de recursos educacionais; implantação de salas de recursos multifuncionais; formação de gestores e demais profissionais da escola; e, da mesma forma, a formação continuada de professores.

Verificando a legislação educacional que trata da inclusão encontrou-se o Programa de Formação Continuada de Professores na Educação Especial - Modalidade a Distância.

O Ministério da Educação, por intermédio da Secretaria de Educação Especial,
desenvolve, em parceria com o programa Universidade Aberta do Brasil - UAB, o
Programa de Formação Continuada de Professores na Educação Especial que tem por
objetivo formar professores dos sistemas estaduais e municipais de ensino, por meio da
constituição de uma rede nacional de instituições públicas de educação superior que
ofertem cursos de formação continuada de professores na modalidade a distância. (BRASIL, 2011)

A Resolução do Conselho de Educação/Conselho Pleno no 1/2002, que institui as Diretrizes Curriculares Nacionais para a Formação de Professores da Educação Básica, em nível superior, curso de licenciatura, de graduação plena, define que as instituições de ensino superior devem prever em sua organização curricular, entre outros itens, o conhecimento sobre o desenvolvimento humano e contemplar especificidades dos alunos com necessidades educacionais especiais, como deficiência (visual, auditiva, física, mental), transtornos globais do desenvolvimento e altas habilidades ou superdotação, ou, ainda, alunos advindos de comunidades indígenas. 
Assim, cada curso de licenciatura deve proporcionar a seus acadêmicos conhecimentos a respeito das mais variadas necessidades educacionais especiais que eles possam vir a se deparar em sua futura ação profissional.

Portanto, essas medidas visam, como escrito no capítulo V da LDB no 9394/96, assegurar aos alunos com necessidades especiais professores do ensino regular capacitados para a integração desses educandos nas classes comuns.

Pelo exposto até o momento, verifica-se que a inclusão de alunos com necessidades especiais é uma realidade nacional e que os professores precisam ter formação para estarem preparados a fim de realizarem a inclusão desses alunos portadores de necessidades especiais em uma sala de aula regular.

\section{Educação matemática inclusiva}

Diante da completude da formação de professores, para esta pesquisa, volta-se o olhar para os professores especialistas da Educação Básica, mais especificamente para o professor de Matemática, convergindo para uma Educação Matemática Inclusiva.

Mesmo que a área de Educação Matemática no Brasil seja considerada uma área nova (com a fundação da SBEM - Sociedade Brasileira de Educação Matemática - em 1988), é evidente que ela está consolidada como uma área participativa nas decisões relativas aos encaminhamentos dos processos e métodos de ensino e de aprendizagem da Matemática no Brasil. Basta olhar, a cada ano, os eventos regionais, estaduais e nacionais realizados; as publicações de veiculação nacional; os programas e cursos de pós-graduação existentes em todas as regiões brasileiras, o número crescente de pesquisadores que desenvolvem trabalhos $\mathrm{e}$ investigações em Educação Matemática, o que nos aponta para um panorama bastante diversificado e produtivo na área.

Diante dessa ampla produção científica da área, em anais de eventos, monografias, dissertações e teses e, também, por meio de artigos científicos veiculados anualmente via periódicos, para esta investigação restringiu-se a busca de informações nos periódicos nacionais representativos da área de Educação Matemática, por perceber que muitas investigações apresentadas em congressos e muitos trabalhos advindos de programas de pós-graduação são depois submetidos aos editoriais das revistas. E também, pelo fato de os autores desenvolverem investigações tendo como aporte revistas da área de Educação Matemática e Ensino de Ciências, optou-se por sistematizar os dados sobre a Educação Matemática Inclusiva, em periódicos nacionais da área de Educação Matemática.

As revistas escolhidas para fazer parte desta investigação foram aquelas apresentadas por Passos (2009b), com exceção do periódico Educação Matemática em Revista (EMR) da Sociedade 
Brasileira de Educação Matemática, por causa da não periodicidade das publicações, conforme se observa em http://www.sbem.com.br/index.php?op=EMR (acesso em 26 de março de 2012), onde consta que a última publicação foi a de número 26, de março de 2009. Assim, para este trabalho as revistas eleitas são: Boletim do Gepem, Bolema, Zetetiké e Educação Matemática Pesquisa.

\section{Análise textual discursiva}

No desenvolvimento desta investigação, para a compreensão do que é apresentado nos artigos, elege-se a análise textual discursiva como uma proposta teórica que pode ser considerada como método de coleta de dados e de análise de dados. A seguir, algumas considerações a respeito desse referencial assumido para este desenvolvimento.

De acordo com Moraes e Galiazzi (2007), o processo da análise textual discursiva é um ciclo composto pelas seguintes etapas: desmontagem dos textos, estabelecimento de relações e captação do novo emergente. Este procedimento é auto-organizado, ou seja, possibilita a produção de novos entendimentos em relação aos fenômenos analisados.

Este método vale-se do potencial dos sistemas caóticos para despontar novos conhecimentos. Conduz-se o objeto de pesquisa até o limite do caos, desmontando, desorganizando e fragmentando os textos; contudo, ao se estabelecer relações entre os fragmentos, novas compreensões emergem a respeito do fenômeno investigado. Estas compreensões são expressas por meio de produções escritas que dependem dos pressupostos teóricos e metodológicos de que o pesquisador apropria-se para observar o novo emergente. A auto-organização ocorre por ser um processode reconstrução de significados, o que permite o surgimento de novos sentidos.

A matéria-prima ou o corpus, o conjunto dos documentos tidos em conta para serem submetidos aos procedimentos analíticos (BARDIN, 2011, p.126), da análise textual é formado por documentos textuais, com imagens e outras expressões linguísticas. Estes documentos já podem estar à disposição do pesquisador, através de: relatórios, publicações em jornais e revistas, resultado de avaliações, atas; ou serem produzidos especialmente para a pesquisa como entrevistas, depoimentos, registros de observações.

A partir do conjunto de textos a serem analisados inicia-se a desconstrução e a unitarização do material. Neste processo surgem as unidades de análise que precisam ser codificadas para indicar sua origem dentro do corpus. Estas unidades podem ser definidas utilizando-se como critério os grandes temas da análise ou ser construídas a partir da análise. Esta etapa pode ser dividida em três momentos: fragmentação e codificação de cada unidade, reescrita de cada unidade dando-Ihe um significado e atribuição de um nome ou título. Ela exige 
do pesquisador envolvimento e impregnação com o corpus e uma leitura aprofundada para que surjam novas considerações a partir do material analisado.

O estabelecimento de relações entre as unidades de análise, ou seja, o processo de categorização consiste em agrupamentos de elementos semelhantes. Neste processo podem ser construídos diferentes níveis de categorias. Estas categorias surgem: pelo método dedutivo - em que as unidades serão agrupadas em conjuntos predeterminados pela teoria que embasa a pesquisa, isto é, são categorias a priori; pelo método indutivo - em que os agrupamentos das unidades surgem a partir do corpus, isto é, são categorias emergentes. O importante é que as categorias construídas propiciem novos sentidos para os textos analisados.

O próximo passo da análise textual discursiva é constituído de uma produção de argumentos em torno das categorias construídas, captando o novo emergente, ou seja, a produção de um metatexto que tem como base os textos originais e que expresse novas compreensões a respeito destes mesmos textos. É necessário examinar o que surge com um olhar abrangente, isto é, este momento não se caracteriza pela síntese, todavia, é um momento de inspiração e de intuição provenientes da impregnação do pesquisador com o tema analisado. Este processo se consolida por meio de retomadas das produções, que estão sujeitas a críticas e reformulações. Nesta comunicação descrevem-se os significados e os sentidos para os textos analisados, possibilitando uma representação fiel do fenômeno e gerando interpretações que se afastam do imediato e que proporcionam a construção de compreensões aprofundadas.

\section{Desenvolvimento da pesquisa}

A seguir, relaciona-se o acervo constituído e algumas informações a respeito das revistas que o compõem, descrevem-se os procedimentos utilizados para o levantamento dos dados do que está sendo publicado nas revistas - segundo o tema sobre o qual o trabalho se debruça - e que pode dar sentido à sistematização de informações vinculadas à coleta dos dados, e, na sequência, institui-se a base de dados para o processo analítico.

\section{Montagem do acervo}

Como já indicado, as revistas elencadas para serem pesquisadas foram: Gepem, Bolema, Zetetiké e Educação Matemática Pesquisa. A seguir, alguns comentários a respeito dessas revistas e a ordem em que elas são apresentadas está relacionada à ordem cronológica em que foram editadas, isto é, da mais antiga para a mais recente.

Boletim Gepem - Gepem: O Gepem é uma publicação do Grupo de Estudos e Pesquisas em Educação Matemática do Instituto de Educação da Universidade Federal Rural do Rio de Janeiro - Seropédica, RJ. 
O Boletim do GEPEM (ISSN-0104-9739) é uma publicação semestral e acolhe, com vistas à divulgação, artigos ou comunicações de experiência (teoricamente fundamentadas) em aula que possam contribuir para o progresso da Educação Matemática ou para a troca de experiências e ideias entre pesquisadores, educadores e professores de Matemática. (GEPEM, 2013)

Boletim de Educação Matemática - Bolema: O Bolema é uma publicação quadrimestral do Programa de Pós-Graduação em Educação Matemática do Instituto de Geociências e Ciências Exatas da Unesp - Universidade Estadual Paulista - Campus de Rio Claro - Rio Claro, SP.

O BOLEMA - Boletim de Educação Matemática (ISSN 0103-636X) é um dos mais antigos periódicos da área de Educação Matemática do Brasil. [...] Com a intenção de disseminar a produção científica em Educação Matemática, o BOLEMA publica artigos, ensaios, resenhas e resumos de dissertações e teses, cujos focos relacionam-se ao ensino e à aprendizagem de Matemática e/ou ao papel da Matemática e da Educação Matemática na sociedade.(BOLEMA, 2013)

Zetetiké: Revista semestral vinculada ao Círculo de Estudo, Memória e Pesquisa em Educação Matemática da Faculdade de Educação da Universidade Estadual de Campinas Campinas, SP.

A Revista Zetetiké tem o objetivo de contribuir para a formação do pesquisador da área
de Educação Matemática por meio da divulgação de pesquisas e estudos realizados por
educadores matemáticos, vinculados a instituições brasileiras ou estrangeiras. (ZETETIKÉ, 2013)

Educação Matemática Pesquisa (EMP): Revista do Programa de Estudos Pós-Graduados em Educação Matemática da Pontifícia Universidade Católica de São Paulo - São Paulo, SP.

A revista Educação Matemática Pesquisa, do Programa de Estudos Pós-Graduados em Educação Matemática da PUC-SP, de regularidade quadrimestral, tem o objetivo de constituir-se em um espaço de divulgação científica da área, em âmbito internacional. Há anos vem contribuindo com esse objetivo e, assim, conseguiu reconhecimento internacional. Sendo considerada excelente na área educacional, dissemina temas contemporâneos - presentes em chamadas de trabalhos e agendas investigativas nacionais ou internacionais recentes - além de trazer interessantes e relevantes questões novas, para o desenvolvimento da área. [...] o projeto editorial da revista 
prioriza artigos científicos, inéditos no Brasil, da área de Educação Matemática, particularmente os relacionados às linhas de pesquisa do Programa: A Matemática na Estrutura Curricular e Formação de Professores; História, Epistemologia e Didática da Matemática e, também, Tecnologias da Informação e Didática da Matemática. (EMP, 2013)

No Quadro 1 tem-se uma visão geral das revistas que compõem o acervo.

Quadro 1: Total de revistas editadas até 2010

\begin{tabular}{|c|c|}
\hline $\begin{array}{c}\text { Nome ou sigla da revista / Ano de } \\
\text { início da publicação }\end{array}$ & $\begin{array}{c}\text { Total de revistas editadas até o } \\
\text { ano de } \mathbf{2 0 1 0}\end{array}$ \\
\hline Gepem/1976 & 57 \\
\hline Bolema/1985 & 41 \\
\hline Zetetiké/1993 & 31 \\
\hline EMP/1999 & $\mathbf{2 6}$ \\
\hline TOTAL & $\mathbf{1 5 5}$ \\
\hline
\end{tabular}

Evidencia-se que o acervo organizado restringe-se às edições das revistas até o ano de 2010, pois os levantamentos foram realizados no segundo semestre de 2011 e a intenção foi a de trabalhar com todas as publicações de cada ano, o que impossibilitou a inclusão dos números editados no ano de 2011 em diante.

\section{Procedimento metodológico}

Para a realização deste trabalho buscou-se uma forma de levantamento de dados que apontasse o que está sendo publicado nas revistas - segundo o tema sobre o qual o trabalho se debruça: Educação Matemática e inclusão - e que pudesse dar sentido à sistematização de informações vinculadas à coleta. Para isso, adotou-se a metodologia apresentada por Passos (2009a) e, a partir dela, realizou-se adaptações que atendessem aos objetivos desta investigação.

Para iniciar a seleção dos artigos, precisava-se de um elemento de busca, também denominado na análise textual por unidade de busca. Essas unidades surgiram dos artigos descritos a seguir:

- FERNANDES, Solange Hassan Ahmad Ali; HEALY, Lulu. A inclusão de alunos cegos nas aulas de Matemática: explorando área, perímetro e volume através do tato. Bolema: Boletim de Educação Matemática / Instituto de Geociências e Ciências Exatas. Departamento de Matemática. Rio Claro: Unesp, 2010. V.23, n.37, pp.1111-1135. ISSN 0103-636X 
- CAMARGO, Eder Pires de; NARDI, Roberto. Contextos comunicacionais adequados e inadequados à inclusão de alunos com deficiência visual em aulas de Mecânica. Ensaio: pesquisa em educação em ciências / Universidade Federal de Minas Gerais. Faculdade de Educação. Centro de Ensino de Ciências e Matemática. Belo Horizonte: UFMG/FAE/CECIMIG, 2010. V.12, n.02, pp.27-48. ISSN 1415-2150

Do primeiro artigo surgiram as seguintes unidades de busca, em ordem alfabética:

- Alunos cegos.

- Aprendizes cegos.

- Aprendizes sem acuidade visual.

- Cegueira.

- Educação especial.

- Educação matemática inclusiva.

- Estímulos hápticos.

- Ferramentas táteis.

- Inclusão.

- Necessidades educacionais especiais.

- Portadores de necessidades educacionais especiais.

- Sala de aula inclusiva.

- Sem acesso ou com acesso limitado ao campo visual.

Do segundo artigo, também em ordem alfabética, as unidades de busca que surgiram foram:

- Aluno cego.

- Alunos com deficiência visual.

- Deficiência visual.

- Discente cego.

- Discente com deficiência.

- Inclusão.

Reunindo os termos destacados anteriormente, tem-se 15 unidades de busca:

- Aluno cego ou alunos cegos ou discente cego ou aprendizes cegos.

- Alunos com deficiência visual. 
- Aprendizes sem acuidade visual.

- Cegueira.

- Deficiência visual.

- Discente com deficiência.

- Educação especial.

- Educação matemática inclusiva.

- Estímulos hápticos.

- Ferramentas táteis.

- Inclusão.

- Necessidades educacionais especiais.

- Portadores de necessidades educacionais especiais.

- Sala de aula inclusiva.

- Sem acesso ou com acesso limitado ao campo visual.

Por conseguinte, esses 15 termos, palavras ou expressões foram assumidos como disparadores na identificação dos artigos sobre Educação Matemática e inclusão nos periódicos selecionados e descritos anteriormente.

A primeira etapa investigativa foi analisar os títulos, as palavras-chave e o resumo dos artigos que compõem as revistas e que estão relacionados com a temática de interesse. Ressalta-se que nos artigos que não havia resumo foi feita a leitura da seção introdução e, em alguns casos, a leitura do artigo completo.

Verificou-se que a lista de tópicos em constituição iria além da já construída, ou seja, para essa investigação seria necessária a composição de uma relação de tópicos própria. Esse movimento foi imprescindível e se justificou, principalmente, em função do que emergia dos resumos na leitura analítica realizada. A partir dessa situação, novas palavras e expressões foram incorporadas e para cada revista analisada uma nova lista era construída. Veja a seguir as listas de palavras e expressões, em ordem alfabética, que emergiram de cada uma das revistas.

Gepem: Deficiência visual. Deficientes visuais.

Boletim de Educação Matemática - Bolema: A mesma indicada anteriormente.

Zetetiké: Adolescentes surdos. Ensino de Matemática para surdos. Surdez. Surdos. 
Educação Matemática Pesquisa (EMP): Alunos cegos. Aprendizes cegos. Cegueira adquirida. Cegueira congênita. Educação especial. Necessidades educacionais especiais.

Ao construir as listas verificou-se que algumas palavras e expressões se repetiam de uma revista para outra. Dessa forma, foram reunidas as palavras e expressões que resultaram das análises preliminares dos quatro periódicos em uma única listagem. A relação a seguir passou a ter 18 itens ao todo:

- Adolescentes surdos.

- Alunos cegos.

- Aprendizes cegos.

- Aprendizes com necessidades educacionais especiais.

- Cegueira adquirida.

- Cegueira congênita.

- Cegueira.

- Deficiência visual.

- Deficientes visuais.

- Educação especial.

- Educação Matemática inclusiva.

- Ensino de Matemática para surdos.

- Inclusão.

- Necessidades educacionais especiais.

- Sala de aula inclusiva.

- Sem acesso ou com acesso limitado ao campo visual.

- Surdez.

- Surdos.

Até o momento descreveu-se o processo de construção das unidades de busca, todavia, algumas considerações podem ser inferidas a respeito dessa listagem. Os resultados provenientes desta análise dos dados serão apresentados em seção própria neste artigo. 


\section{Constituição do corpus}

O procedimento descrito na seção anterior serviu de apoio para a construção da metodologia que culminou na seleção dos artigos que formariam a base de dados, ou seja, o corpus para o desenvolvimento desta pesquisa.

No Quadro 2 destaca-se a quantidade de artigos de cada periódico analisado e a quantidade de artigos que foi identificada e interpretada como do campo desta investigação.

Quadro 2: Quantidade de artigos das revistas e quantidade de artigos sobre Educação Matemática e inclusão

\begin{tabular}{|c|c|c|}
\hline $\begin{array}{c}\text { Sigla ou nome da } \\
\text { revista }\end{array}$ & $\begin{array}{c}\text { Total de } \\
\text { artigos }\end{array}$ & $\begin{array}{c}\text { Total de artigos sobre o } \\
\text { assunto investigado }\end{array}$ \\
\hline Gepem & 322 & 1 \\
\hline Bolema & 260 & 1 \\
\hline Zetetiké & 184 & 1 \\
\hline EMP & 141 & 1 \\
\hline TOTAL & $\mathbf{9 0 7}$ & $\mathbf{4}$ \\
\hline
\end{tabular}

Como se pode observar, o corpus construído é formado por quatro artigos. Na sequência, algumas informações a respeito de cada um desses artigos.

- DIAS, Marcelo de Oliveira; SANTOS, Marcele da Silva. O geoplano como recurso de aprendizagem da geometria plana para deficientes visuais: uma experiência com os alunos do Instituto Benjamin Constant. Boletim Gepem / Grupo de Estudos e Pesquisas em Educação Matemática. Rio de Janeiro: O Grupo, 2010. N.56, pp.105116. ISSN

0104$-9739$

Palavras-chave: Geometria plana. Deficiência visual. Recursos. Geoplano. Simetria.

Resumo (Relato de experiência) - Este artigo tem como objetivo estudar/compreender de que forma o geoplano pode ser um recurso didático que potencializa a aprendizagem de alunos com deficiência visual no ensino de Geometria Plana. Sugere o mesmo como ferramenta didática que favorece a efetiva participação e integração dos alunos através do estímulo de habilidades perceptíveis. Destaca ainda a fundamental importância de envolvimento do professor com o assunto e desperta o olhar para a formação de profissionais especializados e qualificados para lidar com a problemática. 
- FERNANDES, Solange Hassan Ahmad Ali; HEALY, Lulu. A inclusão de alunos cegos nas aulas de Matemática: explorando área, perímetro e volume através do tato. Bolema: Boletim de Educação Matemática / Instituto de Geociências e Ciências Exatas. Departamento de Matemática. Rio Claro: Unesp, 2010. V.23, n.37, pp.1111-1135. ISSN 0103-636X

Palavras-chave: Cegueira. Educação Especial. Educação Matemática. Geometria. Ferramentas Táteis.

Resumo - Desde os anos 90 tem havido um movimento crescente para incluir aprendizes com necessidades educacionais especiais no sistema regular de ensino. Na sala de aula inclusiva de Matemática, professores têm enfrentado a complexa e árdua tarefa de planejar e organizar atividades de aprendizagem para aprendizes que enfrentam uma variedade de desafios. Neste artigo, focamos aprendizes cegos de matemática. Por nossa perspectiva, para construir uma Educação Matemática inclusiva, é necessário entender as particularidades dos processos de aprendizagem daqueles sem acesso ou com acesso limitado ao campo visual. Para tanto, apresentamos neste artigo nossas tentativas de elaborar materiais que permitam a exploração tátil de figuras geométricas, para que aprendizes cegos possam construir entendimentos sobre os conceitos de área, perímetro e volume de uma variedade de formas geométricas. Descrevemos interações dos alunos com o material, deles entre si e com o professor, dando atenção especial aos diálogos matemáticos e aos gestos que emergem durante a realização das tarefas.

- NOgUeIRA, Clélia Maria Ignatius. Surdez, bilinguismo e o ensino tradicional de Matemática: uma avaliação piagetiana. Zetetiké / Universidade Estadual de Campinas. Círculo de Estudo, Memória e Pesquisa em Educação Matemática Faculdade de Educação. Campinas: Cempem, 2008. V.16, n.30, pp.227-245. ISSN 0104-4877

Palavras-chave: Educação Matemática. Surdez. Psicologia Genética. Bilinguismo. Ensino de Matemática para surdos.

Resumo (Relato de experiência) - Este trabalho objetivou investigar o desenvolvimento cognitivo de adolescentes surdos com idade entre 12 e 14 anos, que há pelo menos sete anos eram educados numa abordagem bilíngue e suas possibilidades em relação ao ensino de Matemática da segunda fase do ensino fundamental, cotejando os resultados com os de outra pesquisa, realizada em 1996, que, com os mesmos objetivos, avaliou surdos de mesma idade educados numa abordagem oralista. Os resultados indicaram que tanto os surdos 
"oralistas" quanto os bilíngues não possuíam ainda estruturas cognitivas que lhes possibilitassem compreender os conceitos matemáticos do nível escolar em questão; porém, os surdos bilíngues possuíam grau de escolaridade superior aos da pesquisa anterior, apesar de todos apresentarem defasagens cognitivas de dois anos em relação aos ouvintes, colocando em questão os "sucessos" escolares obtidos pelos sujeitos bilíngues em Matemática.

- FERNANDES, Solange Hassan Ahmad Ali; HEALY, Lulu. Transição entre o intra e interfigural na construção de conhecimento geométrico por alunos cegos. Educação Matemática Pesquisa: Revista do Programa de Estudos Pós-Graduados em Educação Matemática / Pontifícia Universidade Católica de São Paulo. São Paulo: $\quad$ EDUC, $2007 . \quad$ V.9, n.1, pp.121-153. ISSN 1516-5388

Palavras-chave: Educação especial. Intra/inter/transfigural. Transformações geométricas.

Resumo - A preocupação em garantir a todos o direito à Educação tem caracterizado a política atual do Estado em relação às necessidades educacionais especiais. Acreditamos que as necessidades de cada pessoa têm igual importância na construção de uma sociedade justa e com esse olhar temos desenvolvido nossos estudos investigando a apropriação de conceitos geométricos por aprendizes cegos. Neste artigo, descrevemos atividades realizadas com dois sujeitos, um portador de cegueira congênita e outro portador de cegueira adquirida, que envolvem noções de transformações geométricas. Apresentamos as bases teóricas e metodológicas do estudo e ilustramos nossas análises relativas à transição entre os níveis intra e interfigural por meio de alguns episódios de entrevistas.

Cabe destacar que nas descrições anteriores, relativas a cada um dos artigos, os termos sublinhados no título, nas palavras-chave e no resumo, são as unidades de busca encontradas em cada um e que o incluiu no processo de seleção para constituição do corpus analítico. A indicação entre parênteses logo após a palavra 'Resumo' indica que o artigo selecionado refere-se a um relato de experiência. Justifica-se esse destaque e a inclusão desses artigos com características de relato em função da quantidade muito pequena de artigos relacionados ao tema de investigação. A intenção inicial era verificar somente os artigos, contudo, pela ausência de material estendeu-se a seleção também para os relatos de experiência, para que uma quantidade maior de trabalhos pudesse ser selecionada para análise. 
Acredita-se que, diante da análise dos dados, outras informações sobre cada artigo se façam necessárias; quando isto ocorrer, elas serão indicadas.

\section{Análise dos dados}

Como descrito nos procedimentos metodológicos, partiu-se de 15 unidades de busca e, ao final da seleção dos artigos, estas unidades se ampliaram para 18. Esse movimento e seus resultados remetem a algumas considerações.

Diante de um grupo de disparadores de busca composto por um referencial da área de Ensino de Ciências, observa-se que ele não descaracterizou a seleção, em virtude de que dois dos termos evidenciados por ele (aluno cego, inclusão) também se encontram no referencial da área de Educação Matemática. Quanto ao termo deficiência visual, esse também foi encontrado no artigo do Gepem. Os demais termos (cego e deficiência) estão relacionados ao foco temático do que se busca nesta pesquisa.

Lançando mão de uma diversidade de olhares sobre o rol dos 18 termos construídos, e assumindo que esses termos encerram em si o significado global de um contexto, é possível avançar na análise. A partir de um novo olhar tem-se como possibilidade de 'balizamento', o que os pesquisadores da área de Educação Matemática indicam como pertencente ao campo em investigação e, a partir desse novo olhar, foi possível construir três categorias:

- Caracterização do sujeito - está relacionada ao sujeito de pesquisa: adolescentes surdos, alunos cegos, aprendizes cegos, aprendizes com necessidades educacionais especiais, deficientes visuais, surdos, ou, ainda, o sujeito com necessidades educacionais especiais, sem acesso ou com acesso limitado ao campo visual;

- Caracterização das necessidades educacionais especiais - cegueira adquirida, cegueira congênita, cegueira, deficiência visual, surdez;

- Campo investigativo - educação especial, educação matemática inclusiva, ensino de matemática para surdos, inclusão, sala de aula inclusiva.

Nota-se que os pesquisadores deixam evidente no título, nas palavras-chave e no resumo de seus artigos que o público alvo de suas pesquisas são os sujeitos (alunos, aprendizes) com necessidades educacionais especiais, focando a investigação nos processos de aprendizagem da matemática por esses indivíduos.

A segunda categoria indica que, no corpus analisado, foram focadas somente duas deficiências - visual e auditiva -, ou seja, não foram encontrados artigos que apresentassem situações que contemplassem especificidades da deficiência física, mental, transtornos globais do 
desenvolvimento e altas habilidades ou superdotação, que também podem fazer parte de uma sala de aula inclusiva, segundo os documentos governamentais a respeito do assunto.

Na terceira categoria têm-se os termos que caracterizam a Educação Inclusiva na área da Educação Matemática, a partir dos periódicos analisados.

Para esta categorização não se partiu de algo determinado, definido a priori, ela foi construída mediante aquilo que os pesquisadores da área investigaram e cristalizaram nos documentos analisados.

Ao focar a atenção no Quadro 2, observa-se que de um total de 907 artigos avaliados, os quatro artigos analisados não representam $0,5 \%$ do total publicado. Isso aponta para uma produção pouco expressiva para algo que, pelos documentos nacionais, é realidade brasileira há algumas décadas e que os professores precisam ter formação para estarem preparados a fim de realizarem a inclusão desses alunos portadores de necessidades educacionais especiais em uma sala de aula regular.

Verificando o ano de publicação dos artigos tem-se que as pesquisas são recentes, que em 35 anos de publicação (1976-2010) foram encontrados artigos ou relatos de experiência neste campo investigativo somente em 2007, 2008 e 2010. Mesmo as políticas públicas assinalando as mudanças com maior ênfase já na última década de 90.

Dando continuidade ao processo analítico de busca de novos significados associados à Educação Matemática Inclusiva, procurou-se extrair do corpus algo que pudesse expressar as ações investigativas vinculadas ao tema em foco. Assim, buscaram-se os objetivos indicados pelos pesquisadores, autores dos artigos. Acredita-se que com esse movimento pode-se averiguar essas ações investigativas, isto é, podem ocorrer convergências vinculadas a essas investigações representadas pelos verbos.

\begin{abstract}
[...] pelo fato de o objetivo ser aquilo que se pretende alcançar quando se realiza uma ação (conforme Dicionário eletrônico Houaiss da língua portuguesa 1.0), ou seja, o objetivo está relacionado com a ação, e esta ação está encerrada no verbo que compõe o objetivo, pois o verbo é uma classe de palavras que, do ponto de vista semântico, contêm as noções de ação (conforme Dicionário eletrônico Houaiss da língua portuguesa 1.0) ou, ainda, verbo é uma classe gramatical que tipicamente indica ação (conforme versão eletrônica do Dicionário Aurélio - Século XXI). (PASSOS, 2009a)
\end{abstract}

A seguir, os objetivos dos artigos em análise foram transcritos na ordem cronológica de edição, isto é, do mais antigo para o mais recente.

EMP - Analisar aspectos dos diálogos e das ações de dois aprendizes sem acuidade visual, ocorridos durante uma situação instrucional a fim de

R. B. E. C. T., vol 6, núm. 2, mai-ago.2013 ISSN - 1982-873X 
compreender como eles se apropriam de algumas noções de transformações geométricas, mais especificamente de significados para simetria e reflexão.

Zetetiké - Investigar se os surdos bilíngues estariam de posse das estruturas operatórias que permitissem a apreensão dos conteúdos matemáticos de quinta à oitava série.

Gepem - Estudar/compreender de que forma o geoplano pode ser um recurso didático que potencializa a aprendizagem de alunos com deficiência visual no ensino de Geometria Plana.

Bolema - Analisar as estratégias empregadas por aprendizes cegos para a determinação de área e perímetro de figuras planas e o volume de figuras espaciais, e a influência dos instrumentos de medição oferecidos aos alunos para a realização dessas tarefas.

Usando a categorização feita por Passos (2009a), para os verbos que aparecem nos objetivos dos artigos daquela investigação, verificou-se que os verbos sublinhados nos objetivos acima - analisar, investigar e estudar - inserem-se na categoria de ações reflexivas: que faz considerações, ponderações, reflexões a respeito de algo; e o verbo compreender na categoria de ações interpretativas: que faz uma interpretação, explicação. Desta forma, como comentado por Passos (2009a),os próprios pesquisadores estão definindo o que para eles poderia ser considerado ações de investigação vinculadas a essa área de pesquisa e também os termos que caracterizam essa área. Nesta investigação o foco de pesquisa é Educação Matemática Inclusiva; e naquela ocasião foi a formação de professores.

Assim, percebe-se que as investigações nesse campo giram em torno de reflexões referentes a diálogos, práticas, estruturas operatórias, recursos didáticos, estratégias, com foco na aprendizagem dos educandos com necessidades educacionais especiais.

Outra leitura que se pode fazer é em relação às formas de coletas de dados que moveram esses pesquisadores ou colaboradores da área de Educação Matemática que se dedicam a estudar o campo da Educação Matemática Inclusiva. Justifica-se esta proposta pelo fato de que ao se iniciar um trabalho de pesquisa, coloca-se a questão: Como os dados são coletados? Neste caso, como os dados são coletados tratando-se de sujeitos que possuem necessidades educacionais especiais?

Pelo que se pode observar no material analisado, é que em relação às metodologias empregadas pelos pesquisadores, todas estão relacionadas com o desenvolvimento ou aplicação de tarefas, provas ou atividades, acompanhadas por entrevistas, filmagens, registros escritos, gravação de áudio ou videogravação. A partir do corpus analisado pode-se concluir que as metodologias aplicadas pelos pesquisadores são semelhantes. 
Esta última análise, que enfoca a Educação Matemática Inclusiva nos artigos das revistas selecionadas da área de Educação Matemática no período de 1976 a 2010, é justificada pela questão: $O$ que ospesquisadores apresentam em suas pesquisas, referente às considerações finais nos artigos publicados em periódicos nacionais? Assumindo esses termos como disparadores de uma investigação, a seguir estão relacionadas as considerações finais apresentadas nos artigos e que moveram esses pesquisadores em suas buscas e produções.

EMP - Embora os resultados obtidos a partir das análises relativas ao trabalho de dois aprendizes cegos não nos ofereçam bases conclusivas, proporcionam indicadores a serem seguidos em trabalhos futuros com aprendizes portadores de necessidades educacionais especiais, guardadas as diferenças inerentes a cada uma das necessidades educacionais especiais.

Zetetiké - A escola não deve se limitar apenas a "traduzir", para a língua de sinais, metodologias, estratégias e procedimentos da escola comum, mas deve continuar a preocupar-se em organizar atividades que proporcionem o salto qualitativo no pensamento dos surdos.

Gepem - Recebendo estímulos adequados para empregar outros sentidos, como tato, a fala e a audição, o educando sem acuidade visual estará apto a aprender como qualquer outro vidente, desde que respeite a singularidade de seu desenvolvimento cognitivo.

A inclusão é um processo que exige aperfeiçoamento constante por parte do professor, seja em sua formação inicial ou continuada.

Bolema - A proposta de inclusão que defendemos é a que favorece ao aluno incluso integrar-se com seus pares e com o saber. Acreditamos que este tipo de proposta beneficia a todos, deficiente ou não, promovendo uma reestruturação da escola que poderá oferecer uma resposta educativa de qualidade para todos.

Em consonância com o que já foi descrito anteriormente - na categorização construída a partir das unidades de análise provenientes do título, das palavras-chave ou do resumo dos artigos - as conclusões ou as considerações finais reforçam a atenção desses pesquisadores para o processo de aprendizagem, dando voz e vez ao aluno, ao aprendiz com necessidades educacionais especiais. Somente os pesquisadores do artigo divulgado pelo Boletim Gepem fazem um comentário da necessidade de aperfeiçoamento dos professores, nesta área da Educação Inclusiva, em sua formação inicial e continuada, visto que esta colocação inseriu-se como consequência e não como foco da pesquisa. 


\section{Considerações finais}

Esta pesquisa não tem a intenção de indicar conclusões generalistas, mas cooperar com uma visão do que se produz no Brasil a respeito de uma Educação Matemática Inclusiva.

Como indicado pelos editoriais das revistas em seus respectivos sites, elas se preocupam em ser um meio de divulgação da área de Educação Matemática com a intenção de veicular para a comunidade de pesquisadores, educadores e professores de Matemática, artigos, comunicações de experiência, ensaios, resenhas, resumos de dissertações e teses, ou seja, disseminar a produção científica da área.

Pelo encontrado e analisado, verifica-se uma produção bastante reduzida no campo investigativo ao qual este trabalho se debruça. Será que mesmo as revistas tendo como objetivo disseminar a produção científica da área, seus filtros editoriais não priorizam trabalhos na área da Educação Matemática Inclusiva? Ou, realmente, poucos são os pesquisadores que trabalham nesta área?

Será que pesquisas sobre uma Matemática Inclusiva serão encontradas no produto final dos programas de pós-graduação? Ou nos anais de eventos? Será que essa produção será significativa ou permanecerá acanhada como nas revistas analisadas?

Outras indagações se fazem pertinentes: uma das linhas de pesquisa da Capes se intitula Educação Matemática Inclusiva. Portanto, é uma linha que possui subsídios governamentais para realizar pesquisas. Será que poucos se dedicam a tal linha de pesquisa no Brasil? Ou os resultados de pesquisa nesta área são publicados em outros periódicos ou em outras áreas, como a da Educação?

Pelo que foi encontrado verificou-se que as pesquisas, como já dito anteriormente, focam a aprendizagem dando vez e voz ao aluno com necessidades educacionais especiais, mas, e a gestão de matéria e de classe que o professor que trabalha em salas inclusivas deve desenvolver?

\footnotetext{
A função pedagógica de gestão da matéria remete a todos os enunciados relativos ao planejamento, ao ensino e à avaliação de uma aula ou de parte de uma aula. Ela engloba o conjunto das operações de que o mestre lança mão para levar os alunos a aprenderem o conteúdo. (GAUTHIER, 2006, pp.196-197)

A gestão da classe consiste num conjunto de regras e de disposições necessárias para criar e manter um ambiente ordenado favorável tanto ao ensino quanto à aprendizagem. (GAUTHIER, 2006, p.240)
}

Todavia, para que se tenham professores do ensino regular capacitados para a integração desses educandos nas classes comuns, como indicado no capítulo V da LDB no 9394/96, é preciso 
que se tenham pesquisas nesse campo para nortear a formação inicial e continuada de tais mestres.

Esses são alguns pontos que ficam em aberto nessa pesquisa e que já se constituem como problemas para a continuidade desta investigação.

\section{Referências}

BARDIN, Laurence. Análise de conteúdo. Lisboa: Edições 70, 1977; 3.ed., 2004. 223p. ISBN $972-$ $-44-1214-8$

BOLEMA. Sobre o BOLEMA. Disponível em: <http://www2.rc.unesp.br/bolema/?q=sobre >. Acesso em: 14 maio 2013.

BRASIL. Ministério da Educação.Programa de Formação Continuada de Professores na Educação Especial - Modalidade a Distância. Disponível em:

$<$ http://portal.mec.gov.br/index.php?option=com_content\&view=article\&id=14188:programaformacao-continuada-de-professores-na-educacao-especial-modalidade-adistancia\&catid=192:seesp-esducacao-especial>. Acesso em: 17 nov. 2011.

BRASIL. Ministério da Educação. Secretaria de Educação Especial. Política nacional de educação especial na perspectiva da educação inclusiva. 7 jan. 2008. Disponível em:<http://portal.mec.gov.br/arquivos/pdf/politicaeducespecial.pdf>. Acesso em: 17 nov. 2011.

CAMARGO, Eder Pires de; NARDI, Roberto. Contextos comunicacionais adequados e inadequados à inclusão de alunos com deficiência visual em aulas de Mecânica. Ensaio: pesquisa em educação em ciências / Universidade Federal de Minas Gerais. Faculdade de Educação. Centro de Ensino de Ciências e Matemática. Belo Horizonte: UFMG/FAE/CECIMIG, 2010. V.12, n.02, pp.27-48. ISSN $1415-2150$

DIAS, Marcelo de Oliveira; SANTOS, Marcele da Silva. O geoplano como recurso de aprendizagem da geometria plana para deficientes visuais: uma experiência com os alunos do Instituto Benjamin Constant. Boletim Gepem / Grupo de Estudos e Pesquisas em Educação Matemática. Rio de Janeiro: O Grupo, 2010. N.56, pp.105-116. ISSN 0104-9739

EMP. Capa. Disponível em: <http://revistas.pucsp.br/index.php/emp/index>. Acesso em: 14 maio 2013.

FERNANDES, Solange Hassan Ahmad Ali; HEALY, Lulu. A inclusão de alunos cegos nas aulas de Matemática: explorando área, perímetro e volume através do tato. Bolema: Boletim de Educação Matemática / Instituto de Geociências e Ciências Exatas. Departamento de Matemática. Rio Claro: Unesp, 2010. V.23, n.37, pp.1111-1135. ISSN 0103-636X

. Transição entre o intra e interfigural na construção de conhecimento geométrico por alunos cegos. Educação Matemática Pesquisa: Revista do Programa de Estudos Pós-Graduados em Educação Matemática / Pontifícia Universidade Católica de São Paulo. São Paulo: EDUC, 2007. V.9, n.1, pp.121-153. ISSN 1516-5388

GAUTHIER, Clermontet al. Por uma teoria da pedagogia: pesquisas contemporâneas sobre o saber docente. ljuí: Ed. Unijuí, 2006. 480p. ISBN 85-7429-003-3

GEPEM. Normas Editoriais. Disponível em:

<http://www.gepem.ufrrj.br/paginas/home.php?id=Normas>. Acesso em: 14 maio 2013. 
MORAES, Roque; GALIAZZI, Maria do Carmo. Análise textual discursiva. ljuí: Ed. Unijuí, 2007. 224p. ISBN 978-85-7429-609-8

NOGUEIRA, Clélia Maria Ignatius. Surdez, bilinguismo e o ensino tradicional de Matemática: uma avaliação piagetiana. Zetetiké / Universidade Estadual de Campinas. Círculo de Estudo, Memória e Pesquisa em Educação Matemática - Faculdade de Educação. Campinas: Cempem, 2008. V.16, n.30, pp.227-245. ISSN 0104-4877

PASSOS, Angela Meneghello. Um estudo sobre a formação de professores de Ciências e Matemática. 2009a. 139p. Dissertação (Mestrado em Ensino de Ciências e Educação Matemática) - Universidade Estadual de Londrina, Londrina.

PASSOS, Marinez Meneghello. O professor de matemática e sua formação: análise de três décadas da produção bibliográfica em periódicos na área de Educação Matemática no Brasil. 2009b. 328p. Tese (Doutorado em Educação para a Ciência) - Unesp - Universidade Estadual Paulista, Bauru.

ZETETIKÉ. Capa. Disponível em: <http://www.fae.unicamp.br/revista/index.php/zetetike/index>. Acesso em: 14 maio 2013.

Angela Meneghello Passos é doutoranda em Ensino de Ciências e Educação Matemática, pela Universidade Estadual de Londrina - UEL. É professora de Matemática do Instituto Federal do Paraná - Campus Londrina -IFPR. angelamp@sercomtel.com.br

Marinez Meneghello Passos é doutora em Educação para a Ciência, na área de Ensino de Ciências e Matemática, pela Universidade Estadual Paulista "Júlio de Mesquita Filho" - Unesp - Bauru. É professora Associada do Departamento de Matemática da Universidade Estadual de Londrina - UEL - e professora, pesquisadora e orientadora junto ao Programa de Pós-graduação em Ensino de Ciências e Educação Matemática da UEL. marinezmp@sercomtel.com.br

Sergio de Mello Arruda é doutor em Educação pela Universidade de São Paulo - USP - SP. É professor Associado do Departamento de Física da Universidade Estadual de Londrina - UEL - e professor, pesquisador e orientador junto ao Programa de Pós-graduação em Ensino de Ciências e Educação Matemática da UEL. sergioarruda@sercomtel.com.br. Com o apoio do CNPq. 